\title{
EDITORIAL
}

\section{On eggs and chicken}

\author{
J.C. de Jongste*, B. Brunekreef ${ }^{+}$
}

Insight into the relationship between early childhood infections and subsequent development of asthma has long been troubled by the failure to recognise the heterogeneity of "asthma" or recurrent wheeze in childhood. In the last decade, the concept of two or more wheezing phenotypes of childhood asthma has evolved. At the one end of the spectrum, there are children who develop recurrent wheeze associated with allergy who continue to be symptomatic beyond school age, and at the other end there are children who wheeze early in life, mostly with viral infections, and lose their symptoms within a few years time. The latter were shown to be less atopic and less hyperresponsive to bronchoconstricting stimuli [1]. Moreover, epidemiological studies have provided evidence of an inverse relation between lower respiratory tract infections in early life and serum immunoglobulin (Ig)E levels as a marker of allergy in later life [2]. Genetic heterogeneity is supported by studies suggesting that the offspring of atopic asthmatics have a higher risk of developing recurrent wheeze than the offspring from probands with a history of nonatopic "wheezy bronchitis" [3]. It is therefore likely that genetic factors interact with exogenous factors, such as lower respiratory tract infections in early life, to produce specific wheezing phenotypes with or without atopy. The whole spectrum of wheezing disorders is regarded as "asthmatic", but clearly different pathophysiological mechanisms are involved, based on different genetic and environmental pathogenetic factors.

How does the article by Von Mutius et al. [4] appearing in this issue of the Journal, and dealing with the relation between early childhood infections and later asthma, fit in with this view? The association between reported infectious episodes and asthma or recurrent wheeze is strong, with odds ratios reaching values of 7.95 for those with at least six antibiotic courses in the first years of life. In addition, the results confirm the existence of two different "asthma" subgroups, as those with wheezing after many infectious episodes were less likely to be atopic or hyperresponsive and, conversely, those with less infections were more often atopic and hyperresponsive. Furthermore, a history of recurrent infections was associated with fewer symptoms during the preceding year, suggesting a better prognosis for asthma associated with

*Dept of Paediatrics/Paediatric Respiratory Medicine, Erasmus University Medical Centre/Sophia Children's Hospital, Rotterdam, the Netherlands. ${ }^{+}$Environmental and Occupational Health Group, University of Wageningen, Wageningen, the Netherlands.

Correspondence: J.C. de Jongste, Dept of Paediatrics/Respiratory Medicine, Sophia Children's Hospital, P.O. Box 2060, 3000 CB Rotterdam, the Netherlands. Fax: 31104636801. infections in early life. The associations in this study were highly significant, there was a clear relation between numbers of infectious episodes and prevalence of asthma, the groups studied were sufficiently large and response rates were satisfactory. One of the plausible mechanisms of recurrent wheeze after early childhood infections is that the airways become damaged by the infection and hence remain prone to excessive narrowing owing to altered micromechanics. Interestingly, only nonasthmatic children with high numbers of infections had lower lung function values, suggestive of smaller calibre central and peripheral airways, but no such association was found in those with asthma/wheeze. This is consistent with earlier reports showing long-term effects of early airway infection on later lung function [5], but it also suggests that geometric factors in the bronchial tree may not be that important as a predisposing factor for recurrent wheeze. Alternatively, function changes may well be transient and not detectable after symptoms have subsided. An interesting finding is the lack of airway hyperresponsiveness in the group of nonatopics with asthma/recurrent wheeze. This suggests that airway pathology in this subgroup differs from that in atopic asthma, or that factors regulating airway behaviour in these nonatopics had normalized by the time of the studies.

The study has the important flaw of retrospective data collection, with the unavoidable disadvantage of recall bias. The authors correctly point out that recall bias cannot account for strong inverse relationships of infection and atopy or hyperresponsiveness, and it is unlikely that such bias would explain the findings entirely. It would, however, be important to have prospective data analysed in the same way.

What are the implications of these findings? Firstly, it would be extremely important to develop methodology to separate the different asthma phenotypes in individual cases with some confidence. To achieve this, more insight in the pathophysiology and, ultimately, the genotype is necessary. It would be important to know more about the structure and function of the airways, and the immunological mechanisms involved. Few studies have addressed this issue in an "invasive" way, and indeed there is some evidence of differences in airway inflammatory mechanisms between children who wheeze and are atopic, compared to nonatopics who wheeze from viral infections only [6]. It would be interesting to know whether these phenotypes correspond with those defined in the paper by Von Mutius et al. [4]. In children, noninvasive approaches should be further developed to improve the insight into the nature and presence of airway pathology. A better understanding of the individual pathophysiology may 
help to provide proper information to children and their parents, and to select optimal preventive and therapeutic strategies. It would be important to take the heterogeneity of the syndrome into account as far as possible when planning clinical trials; it may well be that certain therapeutic approaches would be effective in one, but not the other phenotype. The presence of atopic sensitization, airway hyperresponsiveness, positive evidence of airway inflammation and, perhaps, matching for a history of recurrent infection in the first years of life may serve to define more homogeneous patient groups. Ultimately, evidence-based therapeutic approaches for different subgroups of the asthma phenotype should become available.

Finally, there is one interesting aspect in this study that deserves greater attention. This is the absence of a negative relationship between early childhood infections and allergic manifestations as well as atopy at school age in the population as a whole. If any relationship was present, it was a positive one, i.e. more hayfever and eczema in children who had serious infections in early childhood. Recently, there has been a great deal of discussion about the "hygiene hypothesis" of early exposure to infections switching the immune system away from developing allergic reactions, mostly based on studies into the relations between atopy and family size, birth order, number of older siblings and day care use [7-11]. The study by VoN Mutius et al. [4] finds an inverse relationship with early infections only in the small subgroup of asthmatics, and it seems that the "hygiene hypothesis" must be viewed critically on the basis of these new data. Although the assessment of early infections was admittedly retrospective and indirect in this study, it is still more direct than assumptions about exposure to infection based upon family size, birth order, etc. As a result more weight would be placed on studies that have looked at infections (more) directly than proxy variables which may be associated with a whole range of other factors that may actually explain the relationship between family size, etc. and atopy. Two more recent publications support this. Another study from former East Germany [12] found more allergic manifestations and atopy in children from small families who had been sent to day care before the age of $1 \mathrm{yr}$ than in children who had been sent to day care after the age of 2 yrs, a finding which is seemingly in coherence with the "hygiene hypothesis", as day care use is known to be associated with exposure to infectious agents [12]. However, skin prick and radioallergosorbent test results in children from large families were similar to those in children from small families, even in the subgroup that went into day care later. A study from the UK [13]; found little association between asthma and family size, and any association present was related to the number of younger rather than older siblings. If, in the end, it is asthma that causes more concern than atopy as such, then this is another finding that should result in a more careful consideration of the effect of infections early in life on the development of asthma. Unfortunately, all three recent studies were retrospective, and relied on proxy variables for measuring exposure to infections rather than on direct assessments. More definite answers will hopefully be provided by the prospective studies that are now being conducted throughout Europe [14].

\section{References}

1. Stein RT, Holberg CJ, Morgan WJ, et al. Peak flow variability, methacholine responsiveness and atopy as markers for detecting different wheezing phenotypes in childhood. Thorax 1997; 52: 946-952.

2. Martinez FD, Stern DA, Wright AL, Taussig LM, Halonen M. Association of nonwheezing lower respiratory tract illnesses in early life with persistently diminished serum IgE levels. Thorax 1995; 50: 1067-1072.

3. Christie GL, Helms PJ, Ross SJ, et al. Outcome for children of parents with atopic asthma and transient childhood wheezy bronchitis. Thorax 1997; 52: 953-957.

4. Von Mutius E, Illi S, Hirsch T, Leupold W, Keil U, Weiland S. Cross-sectional study on the frequency of reported infections in the first years of life and risk of asthma, atopy and airway hyperresponsiveness among school age children. Eur Respir J 1999; 14: 4-11.

5. Shaheen SO, Sterne JAC, Tucker JS, Florey CV. Birth weight, childhood lower respiratory tract infection, and adult lung function. Thorax 1998; 53: 549-553.

6. Stevenson EC, Turner G, Heany LG, et al. Bronchoalveolar lavage findings suggest two different forms of childhood asthma. Clin Exp Allergy 1997; 27: 10271035.

7. Strachan DP, Harkins LS, Johnston ID, Anderson HR. Childhood antecedents of allergic sensitization in young British adults. J Allergy Clin Immunol 1997; 99: 6-12.

8. Strachan DP, Taylor EM, Carpenter RG. Family structure, neonatal infection, and hay fever in adolescence. Arch Dis Child 1996; 74: 422-426.

9. Strachan DP. Hay fever, hygiene, and household size. BMJ 1989; 299: 1259-1260.

10. Von Mutius E, Martinez FD, Fritzsch C, Nicolai T, Reitmeir P, Thiemann HH. Skin test reactivity and number of siblings. BMJ 1994; 308: 692-695.

11. Svanes C, Jarvis D, Chinn S, Burney P. Childood environment and adult atopy: results from the European Community Respiratory Health Survey. J Allergy Clin Immunol 1999; 103: 415-420.

12. Krämer U, Heinrich J, Wjst M, Wichmann H-E. Age of entry to day nursery and allergy in later childhood. Lancet 1999; 353: 450-454.

13. Rona RJ, Hughes JM, Chinn S. Association between asthma and family size between 1977 and 1994. J Epidemiol Community Health 1999; 53: 15-19.

14. Wahn U, Wichmann H-E. Cohort studies on the development of atopy and asthma in infancy and early childhood. Report of an international workshop, Kittendorf, Germany, April 28-30 1996. Belgium, UCB Institute of Allergy, 1997. 